\title{
Analytical study of three cystatin $C$ assays and their impact on cystatin C- based GFR-prediction equations
}

Pierre Delanaye $^{\mathrm{a}}$, Laurence Pieroni ${ }^{\mathrm{b}}$, Christelle Abshoff ${ }^{\mathrm{c}}$, Laurence Lutteri ${ }^{\mathrm{c}}$, Jean-Paul Chapelle ${ }^{\mathrm{c}}$, Jean-Marie Krzesinski $^{\mathrm{a}}$, Bernard Hainque ${ }^{\mathrm{b}}$, Etienne Cavalier ${ }^{\mathrm{c}}$

${ }^{a}$ Department of Nephrology-Dialysis, University of Liège, CHU Sart Tilman, 4000 Liège, Belgium

${ }^{\mathrm{b}}$ Department of Metabolic Biochemistry, Groupe Hospitalier La Pitié-Salpétrière, AP-HP, Paris, France

${ }^{\mathrm{c}}$ Department of Clinical Chemistry, University of Liège, CHU Sart Tilman, 4000 Liège, Belgium

\begin{abstract}
Background: Cystatin C-based equations are used to estimate GFR. However, three cystatin C immunoassays are on the market. Difference in cystatin $\mathrm{C}$ assays could have strong consequences on the accuracy and precision of cystatin C-based equations. We have performed an analytical study of these three assays and studied potential differences between assays on the precision of cystatin C-based equations.
\end{abstract}

Methods: We have studied imprecision, recovery, linearity and interferences of the three immunoassays (nephelometric assay from Siemens and turbidimetric assays from Dako and Gentian). The impact of differences in cystatin $\mathrm{C}$ assays has been studied for the equations published by Levey (Siemens assay) and Grubb (Dako assay).

Results: Analytical performance of the Dako assay is slightly less high. For cystatin C values below $2.5 \mathrm{mg} / \mathrm{L}$, no statistical difference is found between results given by the Dako and the Gentian assays. So, both assays can be used in the Grubb equation. Cystatin C results are different with the Siemens assay. The Levey equation, built with the Siemens assay, can only be used with cystatin $\mathrm{C}$ values measured with this assay. Using the Dako or Gentian assay results in the Levey equation can lead to differences in estimating GFR up to $6 \mathrm{~mL} / \mathrm{min} / 1.73 \mathrm{~m}$. Differences can reach $9.5 \mathrm{~mL} / \mathrm{min} / 1.73 \mathrm{~m}^{2}$ if the Siemens assay is used in the Grubb equation.

Conclusion: The Siemens and Gentian assays seem analytically more valid than the Dako assay for cystatin $\mathrm{C}$ determination. Differences in cystatin $\mathrm{C}$ assays can lead to significant differences in cystatin C-based equations. However, these differences seem less important than the differences observed with creatinine and creatininebased equations.

Keywords: analytical study of cystatin $\mathrm{C}$ assays

Abbreviations: GFR, glomerular filtration rate ; PENIA, particle-enhanced nephelometric immunoassay ; PETIA, particle-enhanced turbidimetric immunoassay ; RF, rheumatoid factor.

\section{Introduction}

Cystatin C, a single 120-residue polypeptide nonglycosylated protein belongs to the cystatin antiproteinase family [1 ]. It is produced by all nucleated cells and has a molecular weight of 13.359 Da. Cystatin C is freely filtered by the glomerule and fully reabsorbed by the tubules where it is catabolized [1]. Determination of Cystatin $\mathrm{C}$ in serum is thus considered as a good marker of the glomerular filtration rate (GFR)[1].

As for creatinine, different equations have recently been developed to estimate the GFR based on Cystatin C results [2-4]. However, one should know that laboratory measurements of cystatin $\mathrm{C}$ are mainly performed with two different methodologies, namely particle-enhanced nephelometric immunoassay (PENIA) and particleenhanced turbidimetric immunoassay (PETIA)[5]. If PENIA is mainly performed with Siemens automates, it is possible to use PETIA kits on different machines. Unfortunately, there is a lack of standardization for cystatin C measurement. Lack of standardization of creatinine results have great consequences on creatinine-based equation results [6,7]. In the same way, potential different results obtained with PENIA or PET1A techniques could potentially lead to larger differences in the estimation of the GFR. In other words, it seems important to study if cystatin $\mathrm{C}$-based equations can be used with all cystatin $\mathrm{C}$ measurement methods or only with the method which has be used in its building [2,4,8]. Several authors have not taken this fact into consideration $[9,10]$ ?

The aim of our study was to compare the performance of the Siemens PENIA on BNII automate with two different PETIA reagents (Dako and Gentian) on the Hitachi 917 automate. We firstly verified the analytical specifications of the manufacturers by evaluating imprecision, recovery, interferences and linearity of the three 
methods. We also measured the potential effect of changing the analytical method in two cystatin C-based equations $[2,4]$.

Table 1 The two cystatin C-based equations studied

\begin{tabular}{ll}
\hline Equation built with the PENIA Siemens method (Levey equation) & eGFR $=76.7 *$ cystatin $^{-1.19}$ \\
Equation built with the PETIA Dako method (Grubb equation) & eGFR $=84.69 *$ cystatin $^{-1.68}$
\end{tabular}

eGFR = estimated GFR

Table 2 Analytical imprecision of the three cystatin $C$ assays

\begin{tabular}{llllllll}
\hline & \multicolumn{3}{c}{ Dako } & \multicolumn{3}{c}{ Gentian } & \multicolumn{2}{c}{ Siemens } \\
\cline { 2 - 5 } \multicolumn{2}{c}{} & $\pm 1 \mathrm{mg} / \mathrm{L}$ & $\pm 2 \mathrm{mg} / \mathrm{L}$ & $\pm 1 \mathrm{mg} / \mathrm{L}$ & $\pm 2 \mathrm{mg} / \mathrm{L}$ & $\pm 1 \mathrm{mg} / \mathrm{L}$ & $\pm 2 \mathrm{mg} / \mathrm{L}$ \\
\hline Intraassay & & & & & & \\
$N$ & 15 & 15 & 15 & 15 & 15 & 15 \\
Mean & 1.018 & 2.818 & 1.064 & 3.035 & 0.991 & 2.722 \\
SD & 0.024 & 0.026 & 0.013 & 0.040 & 0.014 & 0.042 \\
CV $(\%)$ & 2.35 & 0.913 & 1.189 & 1.329 & 1.462 & 1.528 \\
& & & & & & & \\
Interassay & & & & & & & \\
$N$ & 15 & 15 & 15 & 15 & 15 & 15 \\
Mean & 1.030 & 2.810 & 1.073 & 2.961 & 0.987 & 2.090 \\
SD & 0.059 & 0.031 & 0.034 & 0.061 & 0.028 & 0.103 \\
CV $(\%)$ & 5.771 & 1.098 & 3.139 & 2.054 & 2.787 & 3.546 \\
\hline
\end{tabular}

\section{Materials and methods}

The kits were used according to the manufacturers' instructions with calibrators, controls and reagents supplied by the firms. Cystatin C measurement was performed using BN II analyzer (Siemens (ex-Dade-Behring), Marburg, Germany) for the PENIA method. For the PETIA methods, we have used the Dako reagents (Dakocytomation, Glostrup, Denmark) and the Gentian reagents (Gentian, Moss, Norway) on Hitachi 917 analyzer (Roche Diagnostics, Mannheim, Germany).

\subsection{Assay validation}

\subsubsection{Imprecision}

We assessed the intra- and inter-assay precision at two levels ( 1 and $2 \mathrm{mg} / \mathrm{L}$ ) using 15 replicate determinations per level.

\subsubsection{Recovery}

Recovery was determined according to NCCLS guideline EP-6P: five low-concentration and five highconcentration samples were assayed a minimum of five times to establish levels in neat serum. These samples were then mixed at ratios of 1:3,1:1 and 3:1 and re-assayed in replicates with the three methods.

\subsubsection{Linearity}

Linearity was calculated as previously described by NCCLS procedures EP-6A. Briefly, to evaluate the limit of linearity we used pooled sera from patients at high $(7 \mathrm{mg} / \mathrm{L})$ cystatin $\mathrm{C}$ concentrations, which was diluted with $\mathrm{NaCl} 0.9 \%$ to the following percentages of the high pool: $100 \%, 90 \%, 80 \%, 70 \%, 60 \%, 50 \%, 40 \%, 30 \%, 20 \%$ and $10 \%$. Samples were assayed in duplicate in different analytical runs. The polynomial regression analysis was performed for first-, second- and third-order polynomials. The deviation from linearity was calculated between the second-order and the first-order model at every concentration level and was expressed in percentages. Then the deviation from linearity was compared at each level with the stated criteria for error, which was $15 \%$ in our study. 


\subsubsection{Interferences}

We studied the possible interference of hemolysis, lipemia and bilirubin on two pools of serum assessed in duplicate. We also evaluated the possible interference of the rheumatoid factor (RF), as one of the kits (Gentian) was designed with avian antibodies being thus presented as better regarding RF interferences [11,12].

For that purpose, we performed a recovery test according to the NCCLS: five serum samples known to be positive for RF were mixed at ratios of 1:3, 1:1 and 3:1 and reassayed in replicates with the three methods. On the other hand, we treated 10 RF-positive samples with RF-absorbent (IBL, Hamburg, Germany) and tested in parallel, after $1 \mathrm{~h}$ of incubation, the samples treated and untreated [13].

\subsubsection{Method comparison}

To compare the 3 kits, we selected 85 patients. 17 had cystatin $\mathrm{C}$ level $<1 \mathrm{mg} / \mathrm{L}$ (determined with the Siemens assay), 36 had cystatin $\mathrm{C}$ between 1 and $2 \mathrm{mg} / \mathrm{L}$ and 32 had cystatin $\mathrm{C}$ between 2 and $7 \mathrm{mg} / \mathrm{L}$. Cystatin C determinations were performed simultaneously. Comparison of the results was made by a Wilcoxon test. Regression analyses were carried out on each comparison. Data were also analyzed by Bland-Altman plots. As the difference between methods is of crucial importance in the lowest values of cystatin $\mathrm{C}$, we also realized statistical analysis restricting to low cystatin $\mathrm{C}$ values (determined with the PENIA method) and we chose a cystatin C limit of $2.5 \mathrm{mg} / \mathrm{L}$.

\subsubsection{Impact of the assay on the cystatin C-based equation results}

We have calculated the estimated GFR of the patients with the results from the three assays. We have chosen two equations which have been built from large samples. The first equation was built with a "PENIA Siemens cystatin C" from a large chronic kidney disease population $(n=2980)$ (Levey equation) [4] and the second equation was built with a "PETIA Dako cystatin C" ( $n=536)$ (Grubb equation) [2] (Table 1). By Bland and Altman analysis, we analyzed if results of these equations were influenced by the cystatin $\mathrm{C}$ assay used. As the relationship between GFR and cystatin $\mathrm{C}$ is exponential, the potential impact of the different calibrations will be higher in low values. This fact has been largely illustrated for serum creatinine [6]. We have thus restricted the comparisons to cystatin $\mathrm{C}$ values under $2.5 \mathrm{mg} / \mathrm{L}$.

Fig. 1. Cystatin C linearity difference plot for Siemens, Dako and Gentian methods. On the $Y$ axis is the difference between the second-order model and the first-order model relative to the measured value, which describes the degree of nonlinearity. On the $X$ axis is the relative value of each sample. Siemens and Gentian methods are linear from 10\% to $100 \%$ dilution of the high pool (approximately $0.6 \mathrm{mg} / \mathrm{L}$ to 6.1 and $7.1 \mathrm{mg} / \mathrm{L}$, respectively) with deviation from linearity of less than $15 \%$ in this interval. But Dako method exhibits a deviation from linearity of $25 \%$ at the $10 \%$ dilution of the high pool (approximately $0.7 \mathrm{mg} / \mathrm{L}$ ).

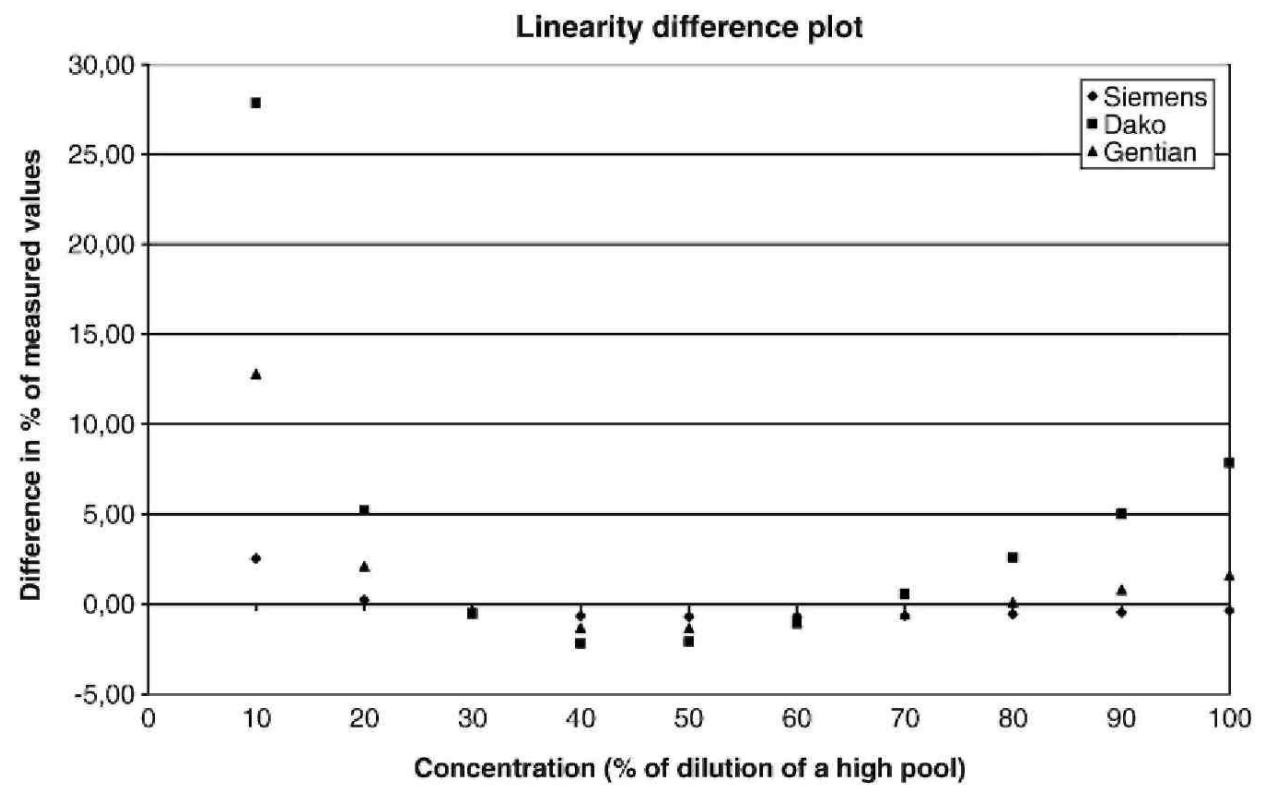




\section{Results}

\subsection{Analytical study}

The CVs were similar for the 3 methods at $2 \mathrm{mg} / \mathrm{L}$. However, we observed a higher CV at $1 \mathrm{mg} / \mathrm{L}$ with the Dako method (5.8\% for the inter-assay) than for the two other methods $(<3.5 \%)$ (Table 2$)$. The recovery results were excellent, as the mean recovery was comprised between 95 and 105\% for the 3 methods. Analysis of the deviation from linearity at each measured level for the 3 methods showed that the Siemens and Gentian methods were linear from 0.59 and $0.70 \mathrm{mg} / \mathrm{L}$ to 6.08 and $7.07 \mathrm{mg} / \mathrm{L}$, respectively, with deviation from linearity of less than $15 \%$. The Dako method was linear from 1.55 to $6.02 \mathrm{mg} / \mathrm{L}$, with an acceptable deviation limit from linearity of 15\% (Fig. 1 ). When diluting sample, a nonlinear relationship was observed for Dako method, with a deviation from linearity of more than $25 \%$ at $0.76 \mathrm{mg} / \mathrm{L}$.

\subsection{Interferences}

Hemoglobin (up to $8 \mathrm{~g} / \mathrm{L}$ ), triglycerides (up to $15.561 \mathrm{mmol} / \mathrm{L}$ ) and bilirubin (up to $1162800 \mu \mathrm{mol} / \mathrm{L}$ ) did not show any significant interference for the 3 methods.

We did not observe any interference of the RF with the 3 methods, as the mean recovery was comprised between 85 and $115 \%$ (Table 3). Moreover, we did not observe any difference between the RF-absorbent treated and untreated RF-positive samples for the 3 methods.

\subsection{Method comparison including all results}

There was no significant difference between the Siemens and the Dako methods (mean \pm SEM of $2.66 \pm 0.22$ $\mathrm{mg} / \mathrm{L}$ versus $2.65 \pm 0.21 \mathrm{mg} / \mathrm{L}$, respectively, $p>0.05)$, whereas we observed significant $(p<0.0001)$ difference between these two methods and the Gentian one $(2.85 \pm 0.24 \mathrm{mg} / \mathrm{L})$. All the results are shown in Table 4 . Regression analyses between the methods are illustrated in Fig. 2. The Bland-Altman graphs are presented in Fig. 3. They show that Gentian produces higher values than the two other methods above $2.5 \mathrm{mg} / \mathrm{L}$.

\subsection{Method comparison restricting to results below $2.5 \mathrm{mg} / \mathrm{L}$}

When we restricted our statistical analyses to the 56 cystatin C results below $2.5 \mathrm{mg} / \mathrm{L}$, we found a significant difference ( $p=0.0014$ between the Siemens and the Dako methods (mean $\pm \mathrm{SEM}$ of $1.31 \pm 0.06 \mathrm{mg} / \mathrm{L}$ versus $1.4 \pm$ $0.06 \mathrm{mg} / \mathrm{L}$ ). The Gentian method results (mean \pm SEM of $1.39 \pm 0.06 \mathrm{mg} / \mathrm{L}$ ) were significantly different from results with the Siemens method $(p<0.0001)$ but not different from results with the Dako method $(p>0.05)$.

All the results are shown in Table 5. The Bland-Altman graphs are presented in Fig. 4.

Table 3 Recovery test with RF-positive samples

\begin{tabular}{|c|c|c|c|c|c|c|c|c|c|}
\hline \multirow[b]{2}{*}{ Sample } & \multicolumn{3}{|c|}{ Siemens } & \multicolumn{3}{|c|}{ Dako } & \multicolumn{3}{|c|}{ Gentian } \\
\hline & $\frac{\text { Expected }}{(\mathrm{mg} / \mathrm{L})}$ & $\frac{\text { Observed }}{(\mathrm{mg} / \mathrm{L})}$ & $\frac{\text { Recovery }}{(\%)}$ & $\frac{\text { Expected }}{(\mathrm{mg} / \mathrm{L})}$ & $\frac{\text { Observed }}{(\mathrm{mg} / \mathrm{L})}$ & $\frac{\text { Recovery }}{(\%)}$ & $\frac{\text { Expected }}{(\mathrm{mg} / \mathrm{L})}$ & $\frac{\text { Observed }}{(\mathrm{mg} / \mathrm{L})}$ & $\begin{array}{l}\text { Recovery } \\
(\%)\end{array}$ \\
\hline Sample 1 & & & & & & & & & \\
\hline $\mathrm{RF}+(64 \mathrm{IU} / \mathrm{mL})$ neat & 0.83 & & & 0.92 & & & 0.88 & & \\
\hline RF negative neat & 0.75 & & & 0.78 & & & 0.78 & & \\
\hline 1RF+:3RF- & 0.76 & 0.76 & 98.7 & 0.82 & 0.84 & 103.1 & 0.81 & 0.82 & 101.9 \\
\hline 1RF+:1RF- & 0.80 & 0.80 & 101.3 & 0.85 & 0.85 & 100.0 & 0.83 & 0.87 & 104.8 \\
\hline 3RF+:1RF- & 0.83 & 0.83 & 102.5 & 0.89 & 0.89 & 100.6 & 0.86 & 0.87 & 101.8 \\
\hline Sample 2 & & & & & & & & & \\
\hline $\mathrm{RF}+(151 \mathrm{IU} / \mathrm{mL})$ neat & 0.76 & & & 0.80 & & & .81 & & \\
\hline RF negative neat & 0.75 & & & 0.78 & & & 0.78 & & \\
\hline 1RF+:3RF- & 0.75 & 0.82 & 109.0 & 0.79 & 0.75 & 95.5 & 0.79 & 0.75 & 95.2 \\
\hline 1RF+:1RF- & 0.76 & 0.87 & 115.2 & 0.79 & 0.79 & 100.0 & 0.80 & 0.79 & 99.4 \\
\hline 3RF+:1RF- & 0.76 & 0.87 & 114.9 & 0.80 & 0.84 & 105.7 & 0.80 & 0.84 & 104.7 \\
\hline Sample 3 & & & & & & & & & \\
\hline $\mathrm{RF}+(884 \mathrm{IU} / \mathrm{mL})$ neat & 0.87 & & & 0.94 & & & 0.92 & & \\
\hline RF negative neat & 0.75 & & & 0.78 & & & 0.78 & & \\
\hline $1 \mathrm{RF}+: 3 \mathrm{RF}-$ & 0.78 & 0.75 & 96.2 & 0.82 & 0.75 & 91.5 & 0.82 & 0.75 & 92.0 \\
\hline 1RF+:1RF- & 0.81 & 0.79 & 97.5 & 0.86 & 0.79 & 91.9 & 0.85 & 0.79 & 92.9 \\
\hline 3RF+:1RF- & 0.84 & 0.84 & 100.0 & 0.90 & 0.84 & 93.3 & 0.89 & 0.84 & 94.9 \\
\hline
\end{tabular}




\subsection{Impact of the assay on the cystatin C-based equation results}

For cystatin C values below $2.5 \mathrm{mg} / \mathrm{L}$, mean $( \pm \mathrm{SEM})$ GFR for the 56 "Siemens cystatin C" with the Levey formula was $67 \pm 4 \mathrm{~mL} / \mathrm{min} / 1.73 \mathrm{~m}^{2}$. If we used other assays within the same formula, our results were $61 \pm 4$ and $60 \pm 4 \mathrm{~mL} / \mathrm{min} / 1.73 \mathrm{~m}^{2}$ for the Dako and the Gentian kits, respectively. Using the Dako kit in the Grubb formula, the mean GFR was $65 \pm 6 \mathrm{~mL} / \mathrm{min} / 1.73 \mathrm{~m}^{2}$. The mean GFR calculated for the same formula were $75 \pm$ 7 and $63 \pm 5 \mathrm{~mL} / \mathrm{min} / 1.73 \mathrm{~m}^{2}$ for the Siemens and the Gentian kit, respectively. Table 6 presents results of mean differences and SD between the eGFR with the reference kit (i.e. PENIA Siemens for the Levey formula and PETIA Dako for the Grubb formula) and with the two other assays. We have presented the Bland and Altman plots to compare the results of the two equations with the three assays for cystatin $\mathrm{C}$ values (Fig. 5). As shown in Fig. 5, differences between the eGFR-equations increased with GFR. This is relevant when the Dako assay is used in the Levey equation (correlation between delta-eGFR and eGFR of 0.46, $p<0.0003$ ), when the Gentian assay is used in the Grubb equation (correlation between delta-eGFR and eGFRof0.46,p<0.0003) and especially when the Gentian assay is used in the Levey equation (correlation between delta-eGFR and eGFR of 0.94 , $p<0.0001)$.

Table 4 Comparison of the three cystatin C assays (all measures included)

\begin{tabular}{|c|c|c|c|c|c|}
\hline & $N$ & Regression & Mean difference & SD of the difference & Limits of agreement \\
\hline & & & $(\mathrm{mg} / \mathrm{L})$ & $(\mathrm{mg} / \mathrm{L})$ & (mg/L) \\
\hline $\begin{array}{l}\text { Dako against } \\
\text { Siemens }\end{array}$ & 85 & $Y=1.0552 \mathrm{X}-0.1338$ & $-0.01(-0.07$ to 0.06$)$ & 0.28 & -0.55 to 0.53 \\
\hline $\begin{array}{l}\text { Gentian against } \\
\text { Siemens }\end{array}$ & 85 & $Y=0.9167 \mathrm{X}+0.0456$ & $0.19(0.15$ to 0.24$)$ & 0.21 & -0.23 to 0.61 \\
\hline Gentian against Dako & 85 & $Y=0.8571 \mathrm{X}+0.234$ & $0.2(0.12$ to 0.29$)$ & 0.39 & -0.56 to 0.96 \\
\hline
\end{tabular}

Table 5 Comparison of the three cystatin C assays (only cystatin C measures below $2.5 \mathrm{mg} / \mathrm{L}$ included)

\begin{tabular}{|c|c|c|c|c|c|}
\hline & $N$ & Regression & $\begin{array}{l}\text { Mean difference } \\
(\mathrm{mg} / \mathrm{L}) \\
(95 \% \mathrm{CI})\end{array}$ & $\begin{array}{l}\text { SD of the difference } \\
(\mathrm{mg} / \mathrm{L})\end{array}$ & $\begin{array}{l}\text { Limits of agreement } \\
(\mathrm{mg} / \mathrm{L})\end{array}$ \\
\hline $\begin{array}{l}\text { Dako against } \\
\text { Siemens }\end{array}$ & 56 & $Y=0.8467 x+0.1251$ & $0.09(0.02$ to 0.16$)$ & 0.26 & -0.41 to 0.59 \\
\hline $\begin{array}{l}\text { Gentian against } \\
\text { Siemens }\end{array}$ & 56 & $Y=1.0247 \times-0.1173$ & $0.08(0.07$ to 0.1$)$ & 0.05 & -0.015 to 0.18 \\
\hline Gentian against Dako & 56 & $Y=0.8908 x+0.1593$ & $-0.01(-0.07$ to 0.06$)$ & 0.24 & -0.48 to 0.47 \\
\hline
\end{tabular}

Table 6 Impact of difference in cystatin C assays on two different cystatin C-based equations for GFR estimating

\begin{tabular}{|c|c|c|c|}
\hline \multirow[t]{2}{*}{ Cystatin $\mathrm{C}$ below $2.5 \mathrm{mg} / \mathrm{L}$} & Mean GFR & Mean difference & SD \\
\hline & $\begin{array}{l}\text { (Siemens) } \\
\left(\mathrm{mL} / \mathrm{min} / 1.73 \mathrm{~m}^{2}\right)\end{array}$ & $\left(\mathrm{mL} / \mathrm{min} / 1.73 \mathrm{~m}^{2}\right)$ & $\left(\mathrm{mL} / \mathrm{min} / 1.73 \mathrm{~m}^{2}\right)$ \\
\hline \multicolumn{4}{|l|}{ A) } \\
\hline eGFR Siemens versus eGFR Dako & 67 & -6 & 13.2 \\
\hline $\begin{array}{l}\text { eGFR Siemens versus eGFR Gentian } \\
B)\end{array}$ & 67 & -6.8 & 6.8 \\
\hline eGFR Dako versus eGFR Siemens & 65 & 9.5 & 19.9 \\
\hline eGFR Dako versus eGFR Gentian & 65 & -1.7 & 17.6 \\
\hline
\end{tabular}

A) The Levey equation (originally built with the Siemens assay) B) The Grubb equation (originally built with the Dako assay). 
Fig. 2. Regression analyses performed for each method comparison. A) Dako against Siemens B) Gentian against Siemens C) Gentian against Dako.

A

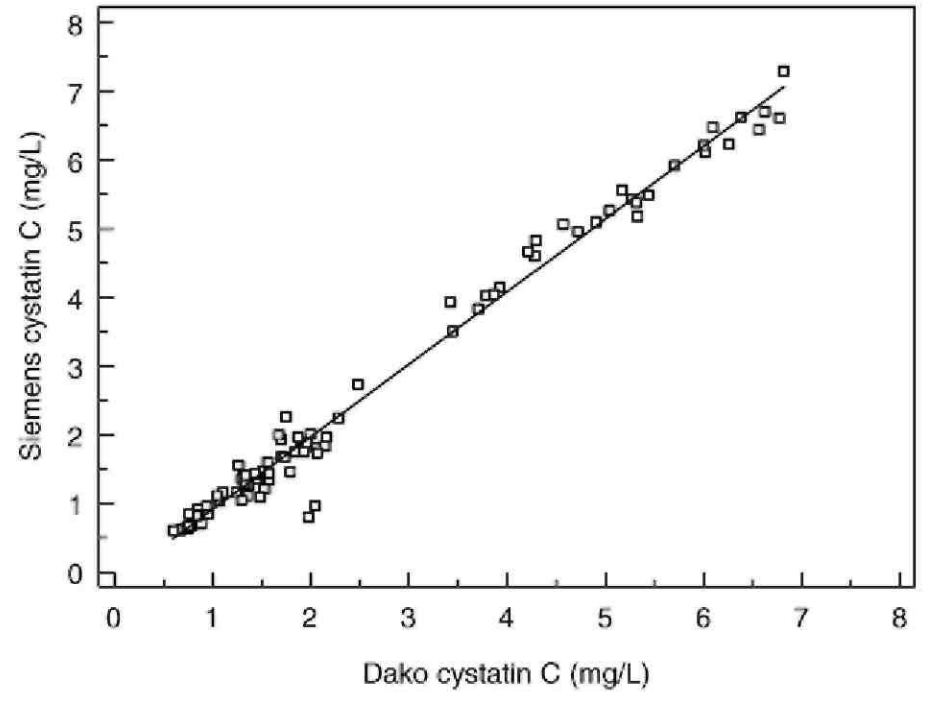

B

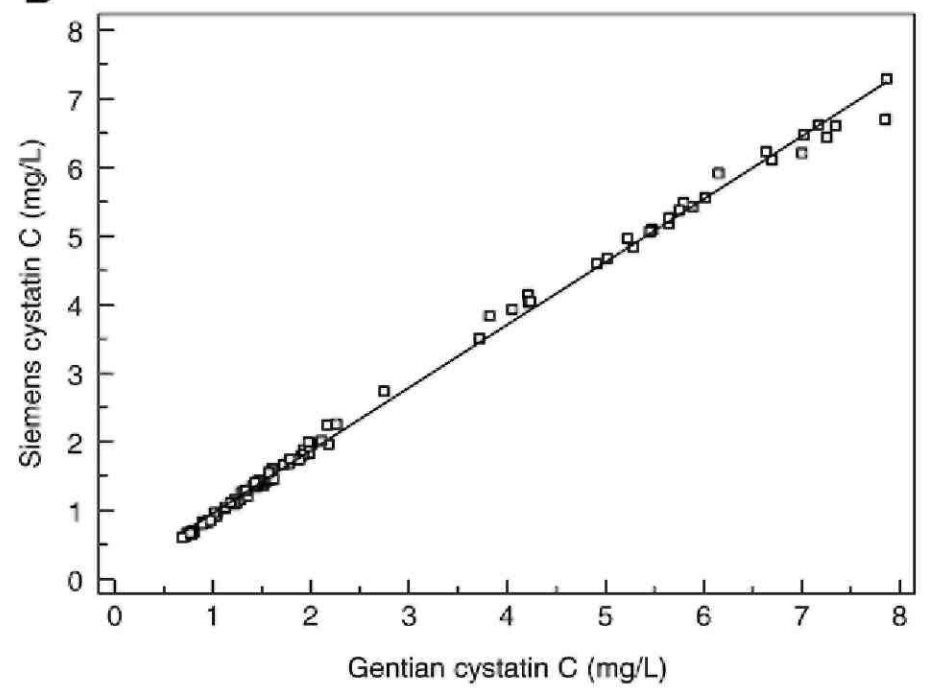

C

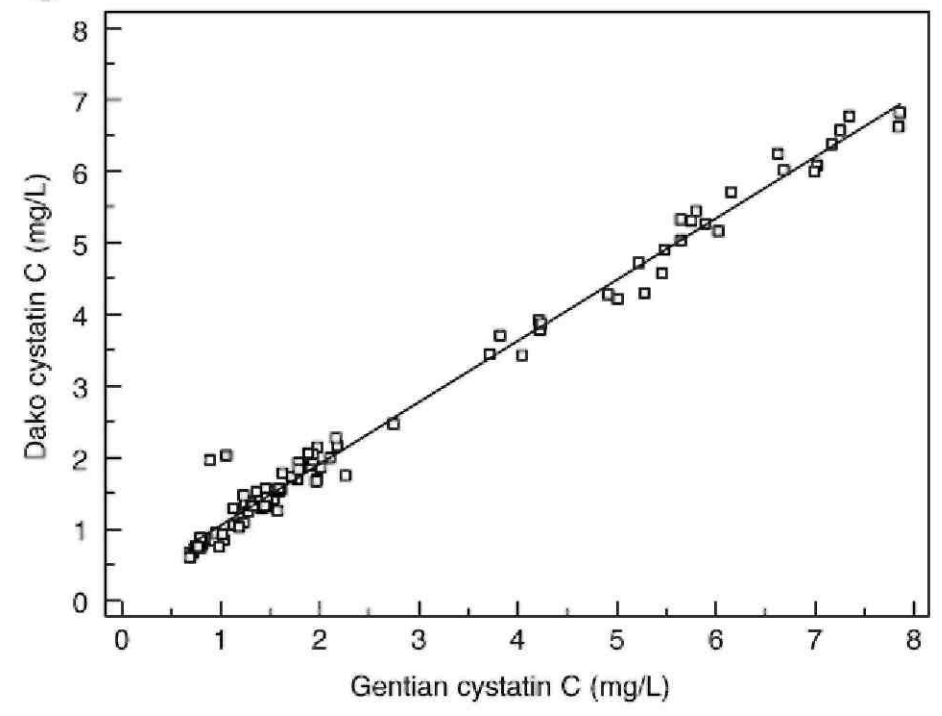


Fig. 3. Bland-Altman plots of Cystatin C determined with Siemens, Dako and Gentian methods on 85 patients. A) Dako against Siemens B) Gentian against Siemens C) Gentian against Dako. All values are expressed in mg/L

A
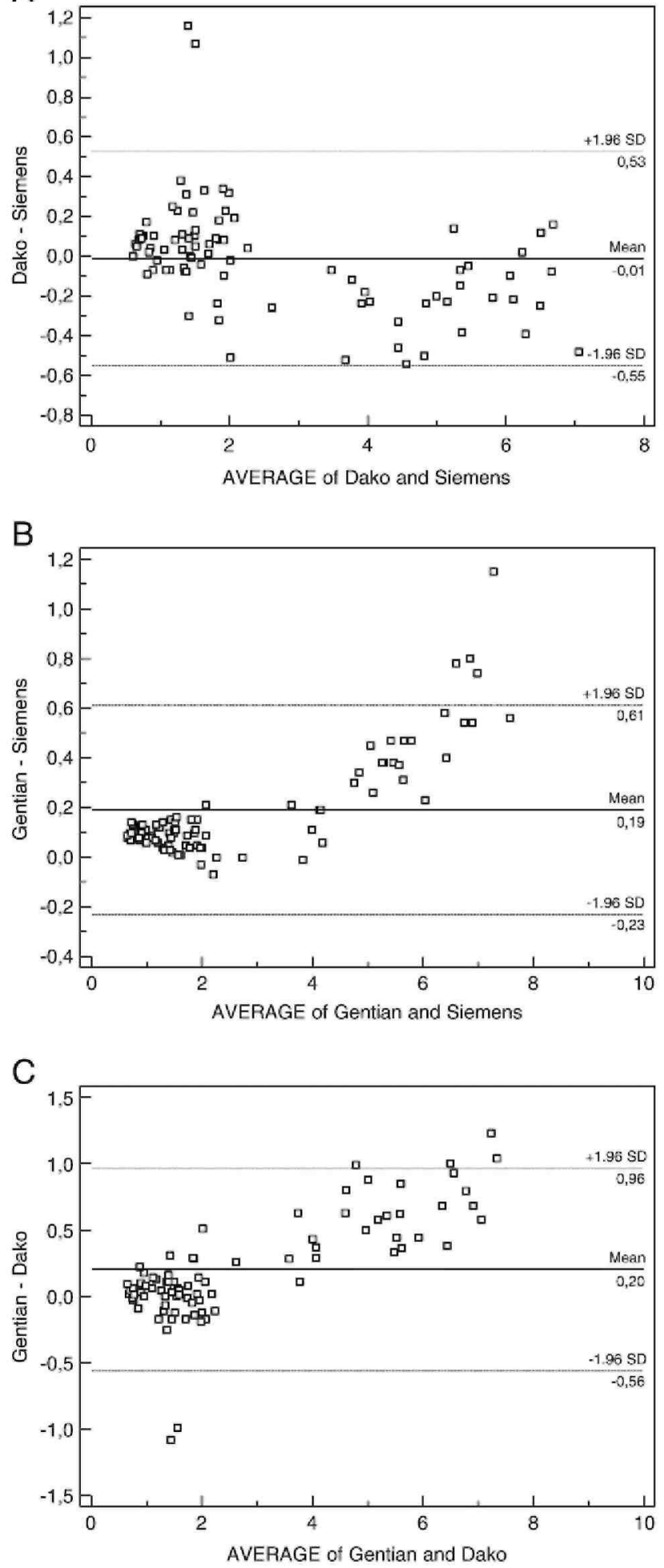
Fig. 4. Bland-Altman plots for comparison of Cystatin C determined with Siemens, Dako and Gentian methods on 56 patients with Siemens cystatin C values below $2.5 \mathrm{mg} / \mathrm{L}$ A) Dako against Siemens B) Gentian against Siemens $C$ ) Gentian against Dako. All values are expressed in $\mathrm{mg} / \mathrm{L}$

A

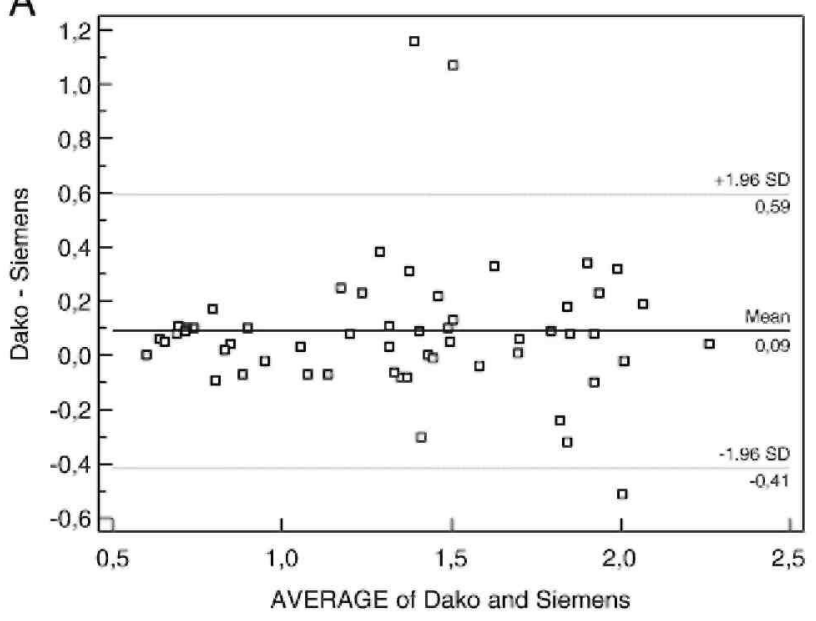

B

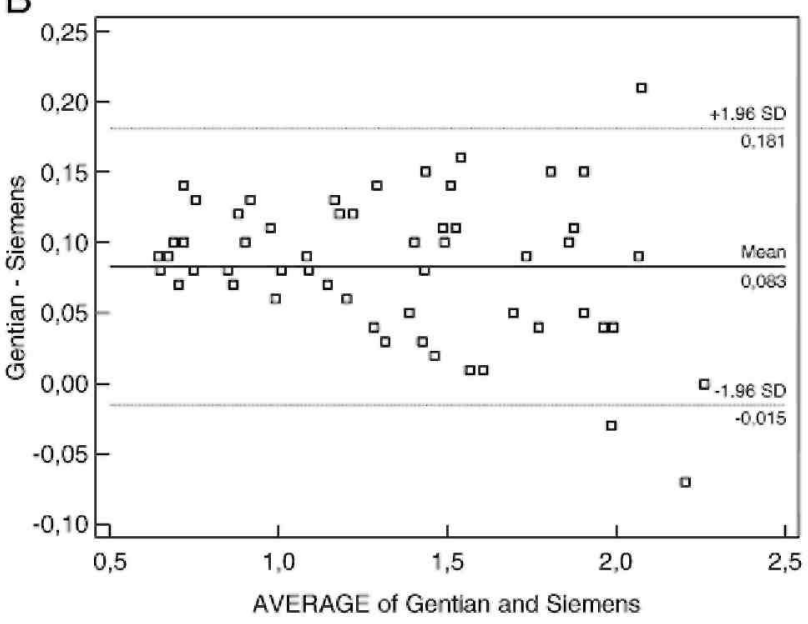

C

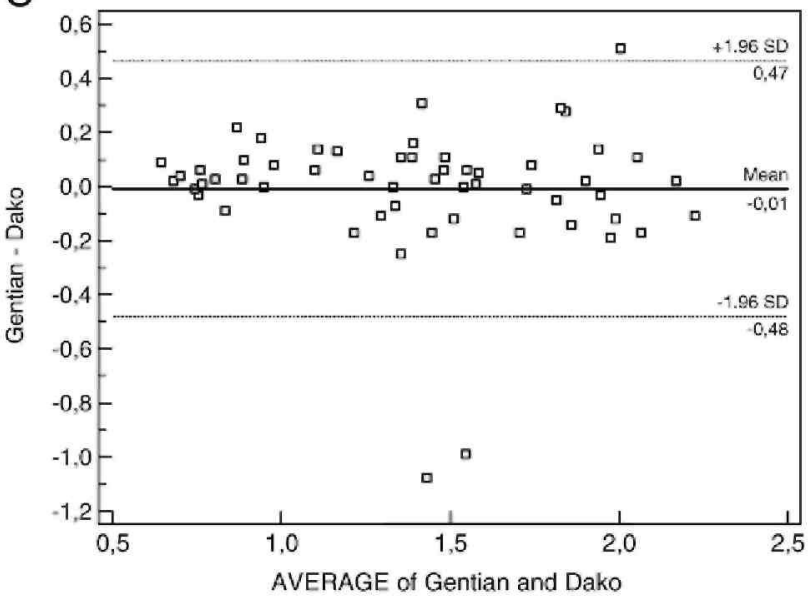


Fig. 5. Bland-Altman plots for comparison of eGFR with different cystatin $C$ assays (restricting to cystatin $C$ values below $2.5 \mathrm{mg} / \mathrm{L})$. On the left: Using the Levey equation (where Siemens is the reference) $(A=$ Siemens against Dako) $(B=$ Siemens against Gentian). On the right: Using the Grubb equation (where Dako is the reference) $(C=$ Dako against Siemens $)\left(D=\right.$ Dako against Gentian). All values are expressed $\mathrm{mL} / \mathrm{min} / 1.73 \mathrm{~m}^{2}$.
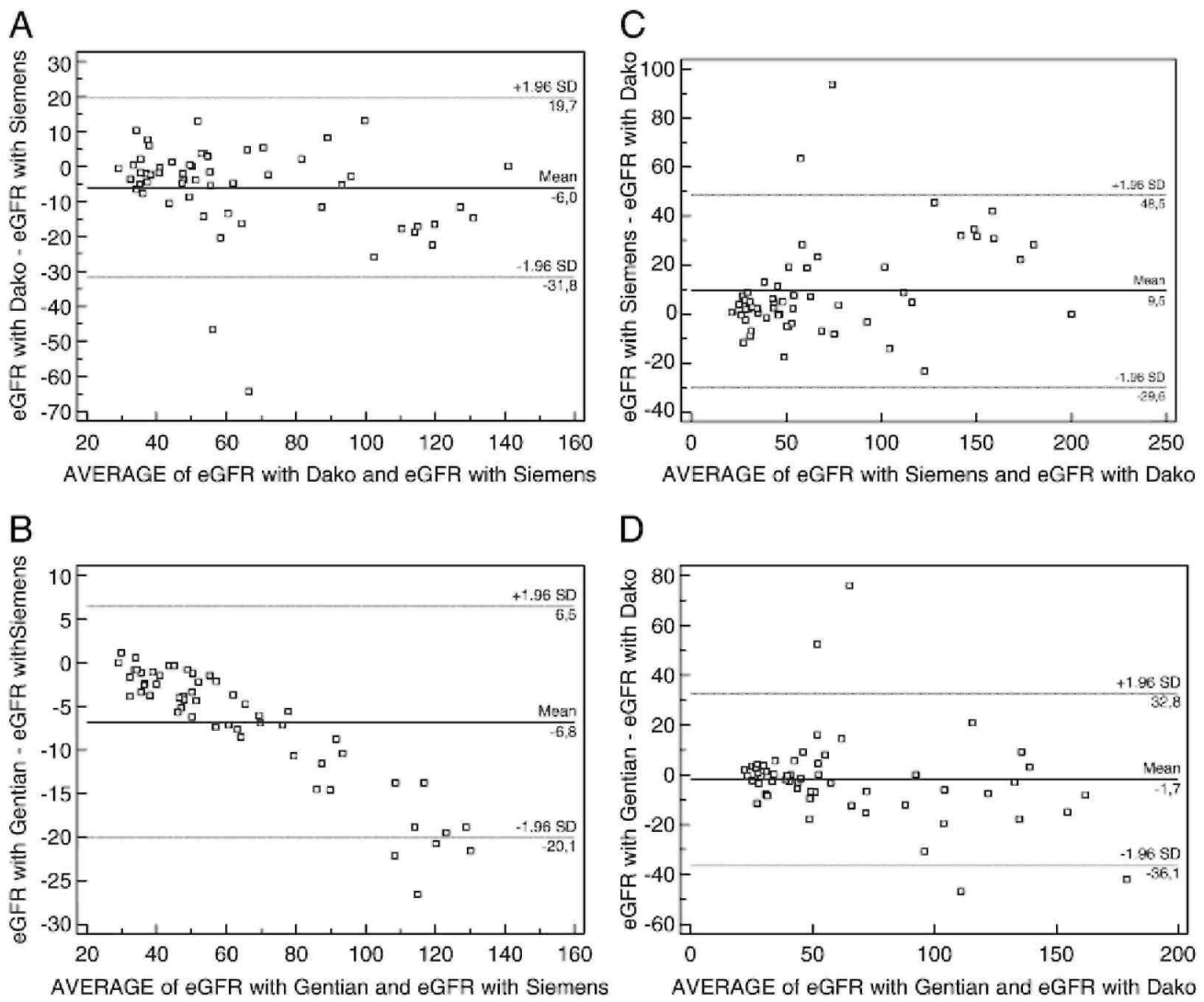

\section{Discussion}

Cystatin C is a new biological marker of GFR [1,14]. Recently, several equations based on cystatin C have been published to better estimate GFR $[2,4]$ We have here compared the analytical performances of cystatin C measurement by three different methods, including two PETIA methods (Gentian and Dako) and one PENIA method (Siemens). We have also evaluated the potential impact of the inter-methods difference on two cystatin C-based equations results. We have chosen these specific equations because both have been elaborated from a large sample of patients but with different cystatin C method (Siemens method for the Levey study and Dako method on the Hitachi Modular P system for the Grubb study) [2,4].

Regarding linearity and recovery, the Siemens assay has excellent performances, with a deviation from linearity of less than $5 \%$ at each level. The Gentian method is also linear within the same range values $(0.7$ to $7 \mathrm{mg} / \mathrm{L})$ but with a deviation from linearity of less than $15 \%$ at low concentration. Moreover, the dilution curve of patient sample obtained with the Dako method deviated from the linearity at the value of $1.5 \mathrm{mg} / \mathrm{L}$, as previously shown [15]. These results have already been published separately for the three methods [5,16-18]. Moreover, regarding the precision of the methods, it seems that the Dako method is less performing than the Siemens and the Gentian methods (CV at $5.8 \%$ versus $3.5 \%$ ). We confirm thus precedent data $[1,5,16]$. This lesser precision will certainly explain that, in the comparison study, SD of the mean difference between Dako and the two other methods are significantly higher than SD of the mean difference between Siemens and Gentian.

Our interferences study results are also of interest. We have recovered the results of precedent studies regarding the absence of significant interferences of the different assays with hemolysis, lipemia and bilirubin $[5,11,18$ 20]. The Gentian assay uses avian antibodies (the two other assays use rabbit antibodies) and some authors have hypothesized that using such avian antibodies will strongly reduce analytical interferences, notably with RF $[11,12]$. For this reason, we have deeply studied potential RF interferences by two different methods. By this way, we did not find any statistical interferences of RF, whatever the methods (and thus the antibodies) used. Our results do not corroborate those of Lamb who described significant RF (concentration unrelated) 
interferences with the Dako system [21]. If as we have shown, no interference occurs with the Dako and the Siemens antibodies, the argument for preferring avian Gentian reagents seems questionable and inapplicable to the cystatin $\mathrm{C}$ assays.

It is well known that the relationship between serum creatinine (as plasma cystatin C) and GFR is exponential. Due to this exponential relationship, little modifications of creatinine linked, for example, to difference in calibration, will have strong consequences on creatinine-based results. This is especially and only relevant in the low or "normal" creatinine ranges [6,22]. Without calibration standardization, estimated GFR results from the MDRD study equations must thus be given as "over $60 \mathrm{~mL} / \mathrm{min} / 1.73 \mathrm{~m}^{2}$ " without specifying the absolute value because lack of precision in these creatinine ranges [22,23], With this "creatinine" experience, we wanted to know if such limitations have to be applied to the "new" cystatin $\mathrm{C}$ equations. In other words, we wanted to know if one can use the Dako or Gentian PETIA results for a cystatin C-based equation built with the Siemens PENIA method and vice versa. We have compared the three assays with the Bland and Altman methods. Once again, as the relationship between cystatin C and GFR is exponential, it is important to differentiate relatively low and high cystatin $C$ values because if differences occur, these differences will occur in low ranges [22,23], This fact is well illustrated by comparison between the Gentian and the Dako assays. When all range of results is included, Gentian measures are significantly different from the Dako measures (with a systematic bias of 0.2 $\mathrm{mg} / \mathrm{L}$ ). However, it clearly appears from the Bland and Altman analysis that Gentian measures systematically and strongly overestimate the Dako method only in highest values. When comparison is restricted to values below $2.5 \mathrm{mg} / \mathrm{L}$, the Gentian results are not different from the Dako method (systematic bias of $-0.01 \mathrm{mg} / \mathrm{L}$ and high correlation). Regarding the Dako measures, it must be underlined that the differences with other assays are mainly characterized by an important dispersion of the results. Indeed, systematic bias between Dako and the two other assays are relatively low (although significant), as it has already been described (in all ranges with the Siemens assay and in the low range with the Gentian assay) [5,16,18,20]. However, the dispersion of the Dako results is higher (illustrated by higher SD around the mean difference and deeper limits of agreement). This is simply explained by the lower analytical precision of the Dako assay.

The potential impact of the three assays on the two cystatin C-based equations used can be analyzed in parallel. In the clinical most useful range of cystatin C (values below $2.5 \mathrm{mg} / \mathrm{L}$ ), differences in both estimated equations results increase when cystatin $\mathrm{C}$ values decreases, reflecting, once again, the exponential relationship between GFR and cystatin $\mathrm{C}$ (little change in cystatin $\mathrm{C}$ induces great changes of GFR in the lowest cystatin $\mathrm{C}$ values). This is particularly relevant when the Gentian assay is used in the Levey equation. We have shown that the Gentian cystatin $C$ results are not different from the Dako results and Fig. 5D confirms that the Gentian cystatin $\mathrm{C}$ can be used in the Grubb equation without significant bias up to an eGFR of $80-90 \mathrm{~mL} / \mathrm{min} / 1.73 \mathrm{~m}^{2}$. Over this eGFR, the differences in estimated GFR with the two assays are rising but the clinical importance of these differences is less critic (distinguish 60 and $70 \mathrm{~mL} / \mathrm{min} / 1.73 \mathrm{~m}^{2}$ is more important then distinguish 130 and 140 $\mathrm{mL} / \mathrm{min} / 1.73 \mathrm{~m}^{2}$ ). Applying the Dako and the Gentian cystatin $\mathrm{C}$ in the Levey equation is maybe more questionable, in term of systematic bias (difference of $\pm 6 \mathrm{~mL} / \mathrm{min} / 1.73 \mathrm{~m}^{2}$ ) and especially in term of precision. The first comparisons published between the Gentian and the Siemens affirming the equivalence between both methods seem thus a little too optimistic [11,24]. Moreover, as it is shown in Fig. 5B, difference in eGFR using either the Siemens or the Gentian kit seems severely dependant on the Cystatin C (and thus eGFR) level. However, it seems still more important not to use the PENIA Siemens in the Grubb formula (difference of \pm 9.5 $\mathrm{mL} / \mathrm{min} / 1.73 \mathrm{~m}^{2}$ ), probably because the power applied to cystatin $\mathrm{C}$ in the Grubb formula (i.e. -1.68 ) is higher than in the Levey formula (i.e. -1.19)(and thus little difference in cystatin $\mathrm{C}$ has greater impact on the formula result).

There are limitations to our study. Firstly, in contrast to the case for creatinine, no internationally recommended calibrator or procedure for determination of cystatin $\mathrm{C}$ levels are available. These tools are urgently needed to be able to reach more uniform results with different cystatin $\mathrm{C}$ assay systems. Secondly, we have limited our analytical analysis to some systems. This point is especially important for the Dako and the Gentian reagents that can be used with other automate (Kone, Abbott...). A vast comparison of all the cystatin $\mathrm{C}$ assays available on the market is thus required [15]. Thirdly, we have studied the potential analytical consequences of cystatin C measurements on two equations results. Our methodology does not allow us to affirm a clear superiority of one equation over the other.

Several conclusions can be drawn from this study. First, the Dako assay used in this study is significantly less precise than the two other assays. This lesser precision has potential consequences on the precision of cystatin C-based equations. Secondly, the Gentian avian antibodies have theoretical advantage regarding RF interference. However, as no significant RF interference has been demonstrated with the two other assays, this advantage is questionable or, in any case, seems minor. Thirdly, we have shown no difference between the Gentian and the Dako assays for cystatin C below $2.5 \mathrm{mg} / \mathrm{L}$ Nevertheless, it must not be concluded that potential differences between assays can only been explained by the detection method used (PETIA versus PENIA) because 
differences in reagents and antibodies seem also of importance [5,15,25], For example, Finney et al. have underlined the effect of different calibrators (purified cystatin $\mathrm{C}$ from human urine for Dade-Behring and human recombinant cystatin $\mathrm{C}$ for Dako) on the assays results [5], Fourthly, for cystatin $\mathrm{C}$ values higher than $2.5 \mathrm{mg} / \mathrm{L}$, the Gentian assay produces significantly higher results than the two other assays studied although other authors do not describe [11]. The lower value of the Gentian highest calibrator, compared to that of Siemens and Dako methods $(6.5$ versus $7.5 \mathrm{mg} / \mathrm{L})$ is probably responsible for a less exactitude in cystatin C measurement within the high concentrations. Lastly, like in creatinine-based equations, we have shown that analytical differences between assays can have consequences on the values of GFR evaluated by cystatin C equations (difference up to 6 to $9 \mathrm{~mL} / \mathrm{min} / 1.73 \mathrm{~m}^{2}$ ). As shown here, results from Siemens are not interchangeable with the two other PETIA assays. However, the impact of difference in assays seems lower for cystatin $\mathrm{C}$ than for creatinine. We suggest that this may be explained by the fact that the exponential relationship between cystatin C and GFR is less powerful than between creatinine and GFR.

\section{Acknowledgement}

We want to thank Mrs Rosalie Bonmariage for her help in the preparation of the manuscript.

\section{References}

[1] Newman DJ, Cystatin C. Ann Clin Biochem 2002;39:89-104.

[2] Grubb A, Nyman U, Bjork J, et al. Simple cystatin C-based prediction equations for glomerular filtration rate compared with the modification of diet in renal disease prediction equation for adults and the Schwartz and the Counahan-Barratt prediction equations for children. Clin Chem 2005;51:1420-31.

[3] Rule AD, Bergstralh EJ, Slezak JM, Bergert J, Larson TS. Glomerular filtration rate estimated by cystatin C among different clinical presentations. Kidney Int 2006;69:399-405.

[4] Stevens LA, Coresh J, Schmid CH, et al. Estimating GFR using serum cystatin C alone and in combination with serum creatinine: a pooled analysis of 3,418 individuals with CKD. Am J Kidney Dis 2008;51:395-406.

[5] Finney H, Newman DJ, Gruber W, Merle P, Price CP. Initial evaluation of cystatin C measurement by particle-enhanced immunonephelometry on the Behring nephelometer systems (BNA, BN II). Clin Chem 1997;43:1016-22.

[6] Coresh J, Astor BC, McQuillan G, et al. Calibration and random variation of the serum creatinine assay as critical elements of using equations to estimate glomerular filtration rate. Am J Kidney Dis 2002;39:920-9.

[7] Van Biesen W, Vanholder R, Veys N, et al. The importance of standardization of creatinine in the implementation of guidelines and recommendations for CKD: implications for CKD management programmes. Nephrol Dial Transplant 2005;21:77-83.

[8] Delanaye P, Cavalier E, Krzesinski JM, Mariat C. Cystatin C-based equations: don't repeat the same errors with analytical considerations. Nephrol Dial Transplant 2008;23:1065-6.

[9] Zahran A, Qureshi M, Shoker A. Comparison between creatinine and cystatin C-based GFR equations in renal transplantation. Nephrol Dial Transplant 2007;22:2659-68.

[10] Ledoux D, Monchi M, Chapelle JR Damas P. Cystatin C blood level as a risk factor for death after heart surgery. Eur Heart J 2007;28:1848-53.

[11] Flodin M, Jonsson AS, Hansson LO, Danielsson LA, Larsson A. Evaluation of Gentian cystatin C reagent on Abbott Ci8200 and calculation of glomerular filtration rate expressed in $\mathrm{mL} / \mathrm{min} / 1.73 \mathrm{~m}(2)$ from the cystatin C values in $\mathrm{mg} / \mathrm{L}$. Scand J Clin Lab Invest 2007;67:560-7.

[12] Hansson LO, Flodin M, Nilsen T, et al. Comparison between chicken and rabbit antibody based particle enhanced cystatin C reagents for immunoturbidimetry J Immunoassay Immunochem 2008;29:1-9.

[13] Cavalier E, Carlisi A, Chapelle JP, Delanaye P. False positive PTH results: an easy strategy to test and detect analytical interferences in routine practice. Clin Chim Acta 2008;387:150-2.

[14] Grubb AO. Cystatin C-properties and use as diagnostic marker. Adv Clin Chem 2000;35:63-99.

[15] Flodin M, Hansson LO, Larsson A. Variations in assay protocol for the Dako cystatin C method may change patient results by $50 \%$ without changing the results for controls. Clin Chem Lab Med 2006;44:1481-5.

[16] Mussap M, Ruzzante N, Varagnolo M, Plebani M. Quantitative automated particle-enhanced immunonephelometric assay for the routinary measurement of human cystatin C. Clin Chem Lab Med 1998;36:859-65.

[17] Newman DJ, Thakkar H, Edwards RG, et al. Serum cystatin C measured by automated immunoassay: a more sensitive marker of changes in GFR than serum creatinine. Kidney Int 1995;47:312-8.

[18] Erlandsen EJ, Randers E, Kristensen JH. Evaluation of the Dade Behring N latex cystatin C assay on the Dade Behring Nephelometer II System. Scand J Clin Lab Invest 1999;59:1-8.

[19] Lewis AV, James TJ, McGuire JB, Taylor RP. Improved immunoturbidimetric assay for cystatin C. Ann Clin Biochem 2001;38:111-4.

[20] Stowe H, Lawrence D, Newman DJ, Lamb EJ. Analytical performance of a particle-enhanced nephelometric immunoassay for serum cystatin C using rate analysis. Clin Chem 2001;47:1482-5. 
Published in: Clinica Chimica Acta (2008), vol. 398, iss. 1-2, pp. 118-124.

Status : Postprint (Author's version)

[21] Lamb E, Stowe H. Rheumatoid factor can interfere with cystatin C measurement. Ann Clin Biochem 2003;40:195-6.

[22] Murthy K, Stevens LA, Stark PC, Levey AS. Variation in the serum creatinine assay calibration: a practical application to glomerular filtration rate estimation. Kidney Int 2005;68:1884-7

[23] Delanaye P, Cavalier E, Krzesinski JM, Chapelle JP. Why the MDRD equation should not be used in patients with normal renal function (and normal creatinine values)? Clin Nephrol 2006;66:147-8.

[24] Sunde K, Nilsen T, Flodin M. Performance characteristics of a cystatin C immunoassay with avian antibodies. Ups J Med Sci 2007;112:21-37

[25] Thuillier F, Demarquilly C, Szymanowicz A, et al. Turbidimétrie ou néphélémétrie: quel choix pour les dosage de l'albumine, l'ApoA, la CRP, l'haptoglobine, l'IgM et la transthyrétine. Ann Biol Clin (Paris) 2008;66:63-78. 